Research Article

\title{
Should wiring be replaced by miniplating of mandibular fractures even in poor developing countries?
}

\section{Peerzada Umar Farooq Baba, Mir Mohsin*, Sheikh Adil Bashir, Mohammad Inam Zaroo, Adil Hafeez Wani, Altaf Rasool, Akram Hussain Bijli, Mir Yasir}

Department of Plastic and Reconstructive Surgery, SKIMS, Srinagar, Jammu and Kashmir, India

Received: 02 June 2016

Accepted: 02 July 2016

\author{
*Correspondence: \\ Dr. Mir Mohsin, \\ E-mail: m_mohsin@ rediffmail.com
}

Copyright: () the author(s), publisher and licensee Medip Academy. This is an open-access article distributed under the terms of the Creative Commons Attribution Non-Commercial License, which permits unrestricted non-commercial use, distribution, and reproduction in any medium, provided the original work is properly cited.

\begin{abstract}
Background: Management of mandibular fractures has evolved significantly over the past few decades from intraosseous wiring, compression plates to miniplates. Our department started using titanium miniplates and we conducted this study to evaluate its feasibility and compare it with wire osteosynthesis.

Methods: This is a prospective randomized study conducted on 150 cases of faciomaxillary trauma due to varied etiology with mandibular fractures; 75 cases each in the wire osteosynthesis group and titanium miniplating groups respectively. The two groups were compared in terms of the postoperative complications, hospital stay, cost of hardware used and patient satisfaction.

Results: Duration of surgery for the fixation of mandibular fractures was significantly reduced in the plating group as compared to the wiring group ( $2.0 \pm 0.4$ versus $2.8 \pm 0.7$ hours). Postoperatively, wound infection was observed in $4 \%$ of cases in the plating group and $16 \%$ in the wiring group, mal-occlusion was seen in $8 \%$ of patients, all in intraosseous wiring group. Mal-union was seen in 6 of the wiring group patients and none in the plating group. Non-union was seen in 3 patients of the wiring group and none of the plating group patients. Patient acceptability and compliance was significantly better in the titanium miniplating group as compared to the Wiring group. Although plating is costly as compared to wiring, the overall advantages outnumber the wiring group.

Conclusions: Titanium miniplating is superior to wiring though comparatively costly but cost alone shouldn't be the consideration in choosing a treatment option even in poor developing countries.
\end{abstract}

Keywords: Mandibular, Fracture, Wiring, Miniplating, Titanium, Osteosynthesis

\section{INTRODUCTION}

Maxillofacial injuries remain a serious clinical problem because of the involvement of a complex anatomical region. ${ }^{1}$ With ever increasing traffic especially two wheelers in developing countries and poor adherence to safety measures like helmets, the incidence of maxillofacial trauma is increasing with every passing day and precious lives are lost day in and day out. Mandible being the only mobile bone of the face, it participates in basic functions such as mastication, phonation, deglutition and maintenance of occlusion. ${ }^{2}$ The prominence, position and anatomic configuration of the mandible are such that it is one of the most frequently injured facial bones after nasal bone. ${ }^{3}$

The first description of mandibular fracture was as early as $1650 \mathrm{BC}$, when an Egyptian Papyrus described the examination, diagnosis and treatment of mandibular fracture. Despite the fact that it is the heaviest and strongest facial bone, mandible has several areas of weakness that are prone to fracture. The weak areas for fractures are the sub-condylar area, the angle and distal body areas, and the mental foramen. ${ }^{4-6}$ 
The goal of treatment in facial fractures is to achieve anatomic reduction and restore function while increasing patient comfort and making postoperative care easier. During the past few decades, the surgical treatment of mandibular fractures has advanced significantly. Rigid internal fixation and early return to function have replaced the use of wire osteosynthesis and prolonged use of maxillomandibular fixation (MMF). Advantages include avoidance of maxillo-mandibular fixation, early mobilization of the mandible, shorter period of hospitalization, increased patient satisfaction and earlier return to the workplace. ${ }^{8}$ Thus, the use of rigid internal fixation obviates these difficulties and it has gained widespread acceptance. ${ }^{9}$

The use of plates for internal fixation of facial fractures is not a new idea. Ewers and Harle quote the first description of mandibular fracture fixation using plates and screws and by Hausmann. ${ }^{10}$ The basic concept of rigid fixation is absolute stability. MiChelet et al and Champy et al suggested that engaging a single cortex is sufficient for rigid osteosynthesis. ${ }^{11}$ Today rigid internal fixation using plating system has gained widespread popularity. Use of tension band wiring to achieve precise reduction and stabilization of fractured segments during rigid fixation has also been described. ${ }^{12}$

Sher-i-Kashmir Institute of Medical Sciences (SKIMS) is one of the only two Tertiary care centers with a Plastic and Maxillofacial surgery department which caters to a population of around 10 million in our state. In our department we were using wire fixation and started miniplate mandibular fixation since 2007 and conducted this study to evaluate the feasibility of titanium miniplating of mandibular fractures and compare it with wire osteosynthesis in terms of the postoperative complications, hospital stay, cost of hardware used and patient satisfaction.

\section{METHODS}

This is a prospective study conducted in the department of plastic and reconstructive surgery, Sher-i-Kashmir Institute of Medical Sciences, Srinagar from December 2007 to December 2014. The research was conducted according to the principles of the Declaration of Helsinki.

The patients of craniofacial trauma (aged 16 years and more), admitted in the department of accident and emergency of this institute were evaluated for mandibular fractures. A total of 150 cases of mandibular fractures were studied. A detailed history with general physical and systemic examination and a thorough local examination was carried out in all patients.

Routine investigations were carried out, besides mandibular x-rays, orthopantomogram (OPG), CT scan of head with facial cuts in all patients. Radiographs of other parts of the body or special investigations were done wherever indicated.
All the patients who needed open reduction to manage their mandibular fractures were included in this study. Informed consent was obtained and treatment was assigned by random allocation (by computer generated numbers) to either titanium miniplate osteosynthesis (group I, $\mathrm{n}=75$ ) or wire osteosynthesis (group II, $\mathrm{n}=$ 75).

All patients were operated under general anaesthesia. Premorbid occlusion was reestablished with manual or instrumental manipulation. Maxillomandibular fixation was then achieved through the application of Erich arch bars, Ivy loops or screw MMF.

In case of titanium miniplate fixation group, two miniplates $(2.0 \mathrm{~mm} 4$-hole or 6-hole) were placed across each fracture (Figure $1 \mathrm{a}, \mathrm{b}, \mathrm{c}$ ). At least two screws were placed on either side of the fracture line in each plate. Maxillomandibular fixation was released; both occlusion and stability of the fracture line were rechecked. The incision site was closed in layers. In those patients who had associated condylar/subcondylar fractures, maxillomandibuar fixation was continued for 10-14 days followed by elastics.

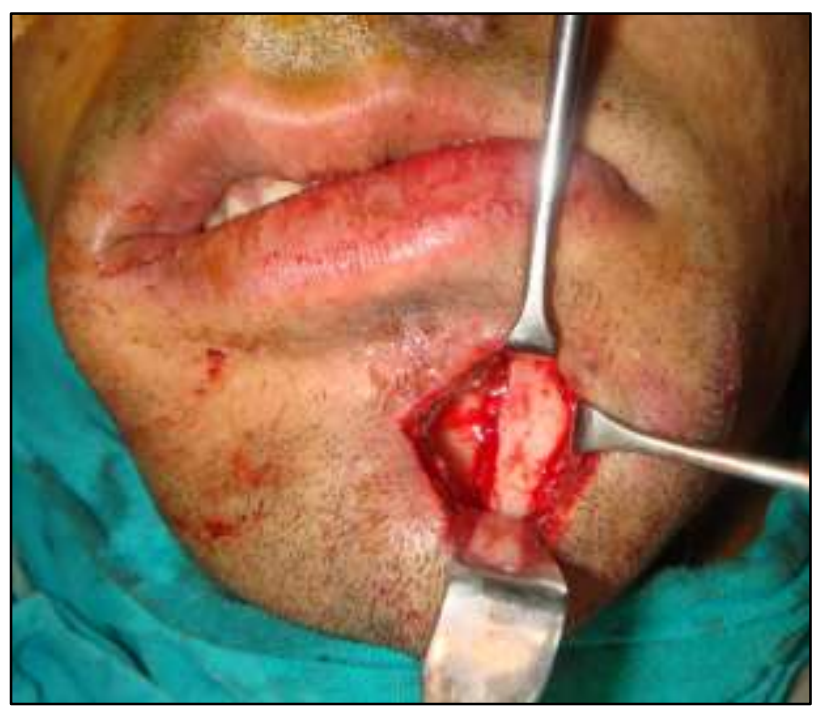

Figure 1: (a) Fracture exposed by intraoral approach and marking of drill hole sites done.

In case of trans-osseous wiring, after the exposure of the fracture site, periosteum was elevated from both the cortices. This was followed by fixation with stainless steel wire $26 \mathrm{G}$, either as figure-of-eight or double wire after MMF in occlusion (Figure $2 \mathrm{a}, \mathrm{b}, \mathrm{c}$ ).

After fixation, occlusion was re-evaluated, and maxillomandibular fixation was continued for 6 weeks. In patients having associated condylar/subcondylar fractures, MMF was kept for two weeks followed by elastics. Wound was closed back in layers. All patients were given advice regarding the maintenance of oral hygiene and diet. 


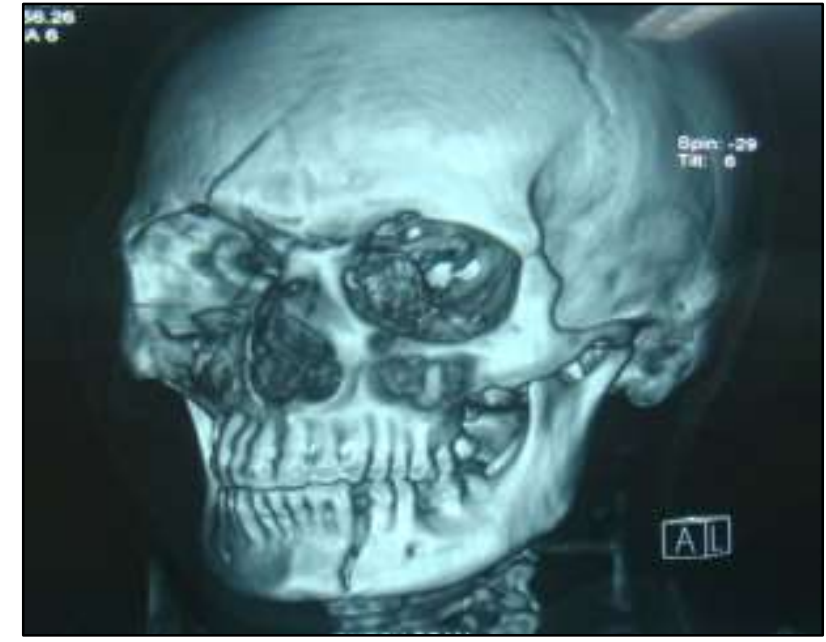

Figure 1: (b) CT scan 3D reconstruction showing right parasymphyseal fracture mandible.

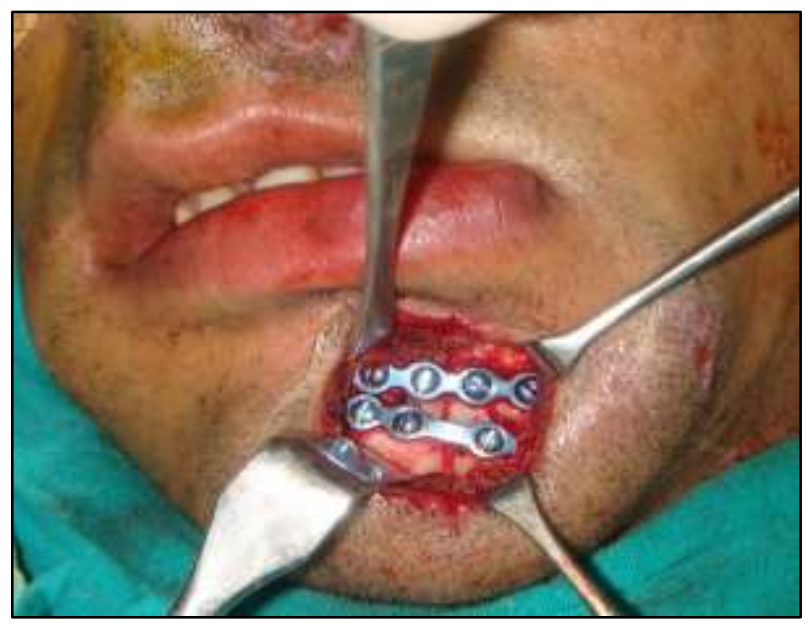

Figure 1: (c) Fracture fixed with two titanium miniplates ( $2 \mathrm{~mm} 4$ hole).

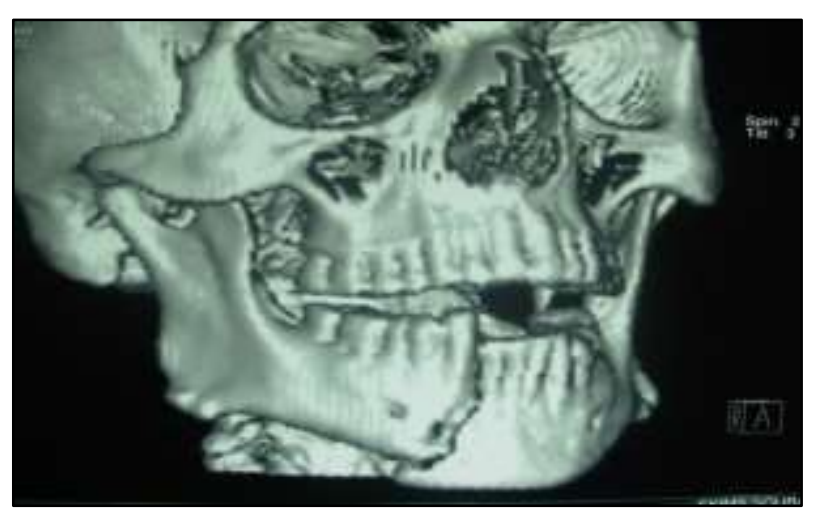

Figure 2: (a) CT scan 3D reconstruction showing right parasymphyseal fracture mandible.

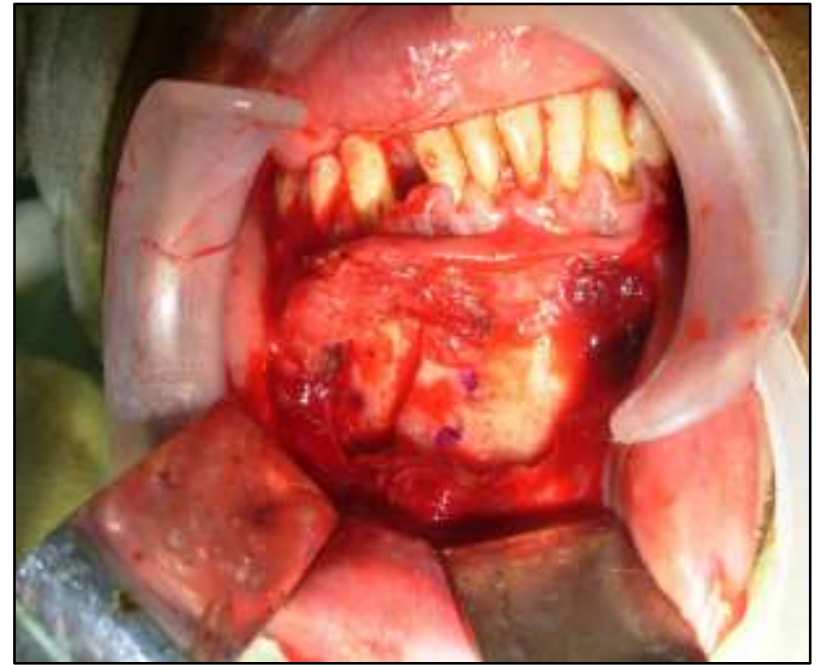

Figure 2: (b) Fracture exposed by intraoral approach and marking of drill hole sites done.

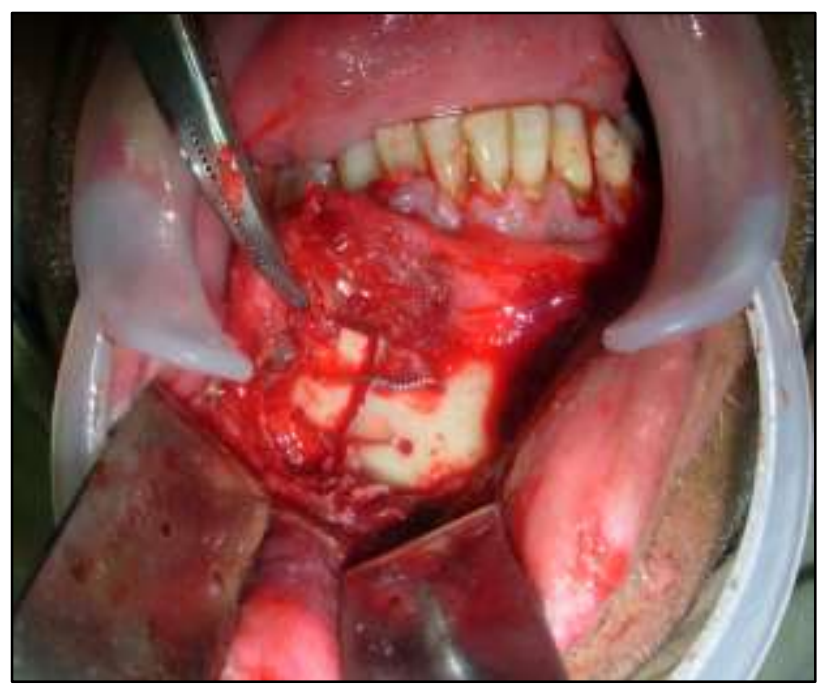

Figure 2: (c) Fracture fixed with two interosseous wires.

Follow up examinations were made initially at weekly intervals and then after every month for at least 1 year. Outcome of the treatment in both groups was recorded in terms of the duration of maxillomandibular fixation, length of hospital stay, postoperative complications, patient comfort and acceptability and cost difference between the two groups - all were assessed and compared. Finally whole data were subjected to statistical analysis.

\section{Statistical analysis}

The whole data was expressed as mean, standard deviation and percentages. The difference between the treatments groups was observed by Yates corrected - Chi square test and Mann-Whitney U-test. $\mathrm{P}$ value was set at $\leq 0.05$. Data was analyzed by using SPSS for Windows 
(version 11.5; SPSS Inc., Chicago, Illinois) statistical software package.

\section{RESULTS}

The age of patients ranged from 16 to 58 years with a mean age of 30.2 years in the Plating group, and 18 to 63 years with a mean age of 31.1 years in the wiring group. Maximum cases (44\%) were in the age group of 16 to 25 years with $74 \%$ (about three-fourths) in the age group of 16 to 35 years.
Eighty four percent patients were males and $16 \%$ females in the Plating group with a male to female ratio of 5.25:1. In the Wiring group, $88 \%$ were males and $12 \%$ females with a male to female ratio of 7.33:1. Overall, $86 \%$ were males and $14 \%$ were females with a male to female ratio of 6.14:1. Forty percent cases presented during summer followed by autumn and spring and least $(8 \%)$ in winter.

Road traffic accident was the leading cause (60\% of cases) followed by fall from height (24\% of cases). A peculiar cause of $6 \%$ of cases in our study was bear maul (Table 1.)

Table 1: distribution of patients as per aetiology ( $N=75$ in each group).

\begin{tabular}{|c|c|c|c|c|c|c|}
\hline \multirow{2}{*}{ Cause } & \multicolumn{2}{|c|}{ Plating group } & \multicolumn{2}{|c|}{ Wiring group } & \multicolumn{2}{|c|}{ Total } \\
\hline & No. & $\%$ & No. & $\%$ & No. & $\%$ \\
\hline Road traffic accidents & 45 & 60.0 & 45 & 60.0 & 90 & 60.0 \\
\hline Fall from height & 15 & 20.0 & 21 & 28.0 & 36 & 24.0 \\
\hline Bear maul injury & 6 & 8.0 & 3 & 4.0 & 9 & 6.0 \\
\hline Blast injury & 3 & 4.0 & 3 & 4.0 & 6 & 4.0 \\
\hline Firearm injury & 3 & 4.0 & - & - & 3 & 2.0 \\
\hline Assault & 3 & 4.0 & - & - & 3 & 2.0 \\
\hline Work-related injury & - & - & 3 & 4.0 & 3 & 2.0 \\
\hline Total & 75 & 100.0 & 75 & 100.0 & 150 & 100.0 \\
\hline
\end{tabular}

$\chi^{2}=3.7, p=0.722(\mathrm{NS})$.

Table 2: Distribution of patients as per the local signs.

\begin{tabular}{|c|c|c|c|c|c|c|c|}
\hline \multirow{2}{*}{ Signs } & \multicolumn{2}{|c|}{ Plating group } & \multicolumn{2}{|c|}{ Wiring group } & \multicolumn{2}{|c|}{ Total } & \multirow{2}{*}{ P value } \\
\hline & No. & $\%$ & No. & $\%$ & No. & $\%$ & \\
\hline Malocclusion & 63 & 84.0 & 45 & 60.0 & 108 & 72.0 & $0.115(\mathrm{NS})$ \\
\hline Open bite & 27 & 36.0 & 3 & 4.0 & 30 & 20.0 & 0.013 (Sig) \\
\hline Cross bite & 12 & 16.0 & 6 & 8.0 & 18 & 12.0 & $0.663(\mathrm{NS})$ \\
\hline Restricted mouth opening & 24 & 32.0 & 18 & 24.0 & 42 & 28.0 & $0.753(\mathrm{NS})$ \\
\hline Trismus & 18 & 24.0 & 15 & 20.0 & 33 & 22.0 & $1.000(\mathrm{NS})$ \\
\hline Step deformity mandible & 18 & 24.0 & 6 & 8.0 & 24 & 16.0 & $0.247(\mathrm{NS})$ \\
\hline Crepitus & 24 & 32.0 & 18 & 24.0 & 42 & 28.0 & $0.753(\mathrm{NS})$ \\
\hline \multicolumn{8}{|l|}{ Exposed mandible } \\
\hline Internally & 15 & 20.0 & 9 & 12 & 24 & 16.0 & $0.059(\mathrm{NS})$ \\
\hline Externally & 12 & 16.0 & 11 & 15 & 23 & 21.0 & $0.118(\mathrm{NS})$ \\
\hline $\begin{array}{l}\text { Anaesthesia in the distribution of inferior } \\
\text { alveolar nerve }\end{array}$ & 12 & 16.0 & 9 & 12.0 & 21 & 14.0 & $1.000(\mathrm{NS})$ \\
\hline
\end{tabular}

Local signs and fracture sites are recorded in Table 2 and 3. Comparative cost of hardware used for fixation is depicted in Table 4.

Postoperatively, wound infection was observed in $4 \%$ of cases in the plating group and $16 \%$ in the wiring group, while mal-occlusion was seen in $8 \%$ of patients, all in intra-osseous wiring group. Mal-union was seen in 6 of the wiring group patients and none in the plating group patients. Non-union was seen in none of the plating group patients, but was seen in 3 patients of the wiring group. Plate exposure occurred in 3 patients and plate prominence was observed in none. Seventh nerve (marginal mandibular nerve) palsy was seen in 3 patients $(2 \%)$, while as inferior alveolar nerve injury was observed in 3 patients of the wiring group.

Duration of surgery for the fixation of mandibular fractures was $2.0 \pm 0.4$ hours in the plating group and $2.8 \pm 0.7$ hours in the wiring group. 
In the titanium miniplating group, $24 \%$ patients were discharged on the first day, $56 \%$ between $2-3$ days and $20 \%$ between $4-7$ days. In the Wiring group, $36 \%$ of the patients were discharged between 2-3 days, $40 \%$ between
4-7 days and $24 \%$ after the first week. Cost of the hardware is compared in Table 5.

Patient acceptability and compliance are shown in Table 5.

Table 3: Distribution of the patients as per the fracture site (anatomical region).

\begin{tabular}{|lllllll|}
\hline \multirow{2}{*}{ Site } & Plating group & \multicolumn{2}{c}{ Wiring group } & \multicolumn{3}{c|}{ Total } \\
& No. & $\mathbf{\%}$ & No. & $\mathbf{\%}$ & No. & \% \\
\hline Symphyseal & 9 & 7.5 & 6 & 5.5 & 15 & 6.6 \\
\hline Parasymphyseal & 57 & 47.5 & 51 & 47.2 & 108 & 47.4 \\
\hline Body & 12 & 10.0 & 15 & 13.9 & 27 & 11.8 \\
\hline Angle & 18 & 15.0 & 12 & 11.1 & 30 & 13.2 \\
\hline Ramus & 3 & 2.5 & 3 & 2.8 & 6 & 2.6 \\
\hline Subcondylar & 9 & 7.5 & 12 & 11.1 & 21 & 9.2 \\
\hline Condyle & 12 & 10.0 & 9 & 8.3 & 21 & 9.2 \\
\hline Total & $\mathbf{1 2 0}$ & $\mathbf{1 0 0 . 0}$ & $\mathbf{1 0 8}$ & $\mathbf{1 0 0 . 0}$ & $\mathbf{2 2 8}$ & $\mathbf{1 0 0 . 0}$ \\
\hline
\end{tabular}

$\chi^{2}=0.9, p=0.988(\mathrm{NS})$.

Table 4: Cost of fixation (hardware).

\begin{tabular}{|c|c|c|}
\hline & Plating group & Wiring group \\
\hline Total no. of cases & 75 & 75 \\
\hline Total no. of fractures fixed & 99 & 87 \\
\hline Total no. plates used & 198 & - \\
\hline Total no. of screws used & 376 & - \\
\hline Total no. of wires used & - & 87 \\
\hline Cost of fixation of one fracture & 3500 & 300 \\
\hline Total cost of plates and screws/wires (rupees) & 346500 & 26100 \\
\hline
\end{tabular}

One Dollar $=67$ Indian rupees.

Table 5: Patient acceptability/satisfaction (using a scale from 0 - 10).

\begin{tabular}{|lllllll|}
\hline & Plating group & & Wiring group & \multicolumn{2}{c|}{ Total } \\
& No. & $\mathbf{\%}$ & No. & \% & No. & \% \\
\hline Excellent & 30 & 40.0 & - & - & 30 & 20.0 \\
\hline Good & 36 & 48.0 & 6 & 8.0 & 42 & 28.0 \\
\hline Fair & 9 & 12.0 & 6 & 8.0 & 15 & 10.0 \\
\hline Poor & - & - & 63 & 84.0 & 63 & 42.0 \\
\hline Total & $\mathbf{7 5}$ & $\mathbf{1 0 0 . 0}$ & $\mathbf{7 5}$ & $\mathbf{1 0 0 . 0}$ & $\mathbf{1 5 0}$ & $\mathbf{1 0 0 . 0}$ \\
\hline
\end{tabular}

$\chi^{2}=38.3, \mathrm{p}=0.000(\mathrm{Sig})$.

\section{DISCUSSION}

Majority of our patients (44\%) were in the age group of 16 to 25 years with $74 \%$ of our patients (about threefourths) in the age group of 16 to 35 years. This is in agreement with Patrocinio et al, Kellman et al, Zachariades et al and Ozgenel et al who observed a peak occurrence in young adults aged 20 to 29 years. ${ }^{2,13-15}$ This predominance is due to the fact that this age group is more prone to road traffic accidents and violence.
Most of our patients ( $86 \%$ ) were males with a male to female ratio of $6.1: 1$. This male predominance is in agreement with most of the authors. ${ }^{2,4,9,11,13-23}$

Road traffic accidents were the major cause (60\%) of mandibular fractures in our study followed by fall from height $(24 \%)$. A unique cause of mandibular fractures in our study was bear maul injuries accounting for $6 \%$ of cases. Differences between populations regarding the causes of maxillofacial fractures have been reported to be due to socioeconomic, geographic and cultural 
differences. In our study, road traffic accidents were responsible for the majority of mandibular fractures which is consistent with the findings in many developing countries where road traffic accident remains the commonest cause of maxillofacial fractures. ${ }^{2,22}$ This is at variance with reports from developed countries where assaults are now becoming the commonest cause of injury. $^{11,16,23}$

Motorcyclists who sustained facial fractures had not worn helmets during the accident. Similarly, majority of accident victims were not using seat belts at the time of injury, emphasizing the need for their mandatory use.

Maximum number of injuries (40\%) occurred during summer followed by autumn and spring and least (8\%) in winter which again is in agreement with Malara et al who reported majority of cases occurring in spring and summer with least cases in winter. ${ }^{1}$ In addition, in our state, environmental conditions are such that during winter people like to remain indoors and overall traffic movement is less, especially motorbike plying comes to a virtual halt. As a result, incidence of road traffic accidents decline during winter. In addition, fall from height being the second leading cause in our study; fall from walnut trees is peculiar in our valley during the last month of summer, and early autumn (harvesting season), leading to increased incidence of cases during these months.

Majority of our patients $(47.4 \%)$ had parasymphyseal fracture followed by angle (13.2\%), body (11.8\%), condyle and subcondyle (9.2\% each), symphysis $(6.6 \%)$ and ramus $(2.6 \%)$. This is in accordance with Kellman et al, Theriot et al, Abbas et al, Ozgenel et al who also observed parasymphyesal fracture as most common fracture followed by angle, body, condyle-subcondyle, symphysis and ramus. ${ }^{11,13,15,21}$ This is in contrast to the observations made by Iizuka et al and Adeyemo et al who noted angle and body as the most common sites of fracture followed by parasymphysis, condyle and symphysis. $^{18,23}$

Operative time was reduced in the titanium miniplating osteosynthesis group as compared to the wire osteosynthesis group which was statistically significant, inspite of the fact that most of the patients with complex associated injuries were managed with titanium miniplate fixation. Reason for this is that wiring requires more dissection, exposure of two surfaces (buccal as well as lingual), wider exposure, and wires are tedious to apply. This is in contrast to what had been reported by Leach et al that plate fixation was associated with slightly longer than average hospital stay and a significantly longer operative time. $^{24}$

Twenty four percent of plating group patients was discharged on the $1^{\text {st }}$ postoperative day while $80 \%$ were discharged by the $3^{\text {rd }}$ day. Only $16 \%$ of wiring group patients were discharged within 3 days and $24 \%$ of patients were discharged during the $2^{\text {nd }}$ week. Patrocinio et al reported that the time until discharge ranged a lot, depending on patient's condition and severity of associated injuries ranging from the same day to 82 days. ${ }^{2}$ Our findings are in agreement with those of Renton et al who showed significantly shorter hospital stay in plating group. ${ }^{16}$ Contrary to ours, Leach et al and Hoffman et al reported that plate fixation was associated with longer than average hospital stay. ${ }^{17,24}$

In our study, the overall incidence of wound infection was $10 \%$, with $4 \%$ of infection rate in the plating group and $16 \%$ in the wiring group. This is in agreement with the published literature, reporting the infection rate with plates to be between $3 \%$ and $23 \%$. On the other hand, the reported rate of infection of mandibular fractures treated with conventional methods is between $4.4 \%$ and $17 \%$. $^{14}$ Sindet-Pedersen et al reported that titanium miniplate fixation is associated with a low complication rate and reduced morbidity as compared to the conventional treatment. $^{25}$ Likewise, Renton et al reported a significantly reduced complication rate in plating group compared with trans-osseous wiring group. ${ }^{16}$ The low infection rate with plates is related to low mobility of the fragments. In addition, metal plates can be used in the presence of infection because they provide mechanical immobility which is the principal factor for success in treating infected fractures. ${ }^{14}$ Theriot et al and Leach et al reported that the number of infections was higher with plates than with wires. ${ }^{11,24}$ Hoffman et al reported a comparable infection rate in the two groups. ${ }^{17}$

In our study, malocclusion was seen in $8 \%$ of patients, all in intraosseous wiring group. Ozgenel et al and Fox and Kellman, both reporting malocclusion rate of $5.9 \% .^{8,15}$ Mal-union was seen in six of the wiring group patients and none in the plating group, while the reported malunion rate for current plating procedures range from $0.5 \%$ to $1.9 \% .{ }^{19}$ Non-union was seen in none of the plating patients, as is also reported by Fox and Kellman and Bolourian et al. ${ }^{8,9}$ However, non-union was seen in three patients of the wiring group.

In our study, plate exposure occurred in 3 patients and plate prominence was observed in none. This is in agreement with Rubin et al who after reviewing the literature reported that the average incidence of the implant becoming exposed is $2 \%$ with plate prominence reported in none. ${ }^{26}$

The use of miniplates is a standard technique in the treatment of facial fractures. Miniplates aim to fix the bone ends solely in the reduced position without compression. Because the plates are very thin, they achieve good aesthetics and are scarcely palpable. It has been advocated that engaging a single cortex (monocortical screws) is adequate. ${ }^{27}$ Reviews of large series of patients have consistently found relatively lower infection rates and improved overall results when plate fixation has been utilized. The advantages of plate 
fixation include absolute immobilization of the fracture site. Also the ideal treatment for comminuted fractures of the mandible is by means of ORIF with titanium miniplates. In fractures with extensive displacements, by exposing the fracture, one is able to reduce all these comminuted fragments to a pre-traumatic anatomic position. 28 Though inter-osseous wiring is simple and inexpensive, it needs more exposure than rigid fixation techniques. It fixes the fracture none rigidly and tends to loosen because of the pressure on thin wire. Even the best inter-maxillary fixation and wire fixation allows some motion, which contributes to both non-union and infection. Threading the wire through both fragments can be difficult and must be repeated if the wire is broken during tightening. ${ }^{14}$

A major advantage of titanium miniplate osteosynthesis is the avoidance or reduction of inter-maxillary fixation duration leading to an overall general improved postoperative function including respiratory function. Inter-maxillary fixation is fraught with dangers such as vomiting and aspiration even in otherwise healthy patient. Maintenance of weight and mouth opening are also better. ${ }^{16}$ There is better patient compliance and improved nutrition during the healing period. There is both clinical and experimental evidence that prolonged inter-maxillary fixation results in muscular atrophy and stiffness of temporomandibular joint. ${ }^{17}$ Furthermore, it is safer in the neurologically damaged patient, particularly in the presence of seizure disorder; it may also eliminate the need for tracheostomy. Certain brain injured patients actually do not tolerate inter-maxillary fixation, and may often break and dislodge appliance, and avoidance of inter-maxillary fixation will improve the likelihood of success. In addition, it can save people in certain profession (e.g. sales) from loss of livelihood. ${ }^{13}$

The limitation of these plates is the cost. Reported results from several studies focusing on economic analysis have been inconsistent. Investigators including Hoffman et al, Thaller et al, Brown et al and Dodson and Pfeffle have argued that ORIF may be the more cost-effective approach for treating mandible fractures if the costs of treating potential complications are considered. In contrast, El-Degwi and Mathog, Schmidt et al and Shetty et al suggest that the use of MMF offers considerable cost-savings over ORIF. Our study results are consistent with the findings of other investigators (Schmidt et al, Abubaker and Lynam), that the cost of ORIF is nearly threefold higher than conventional MMF and wiring. ${ }^{29}$

\section{CONCLUSION}

A major advantage of the Titanium miniplate osteosynthesis is the altogether avoidance or reduction of the period of inter-maxillary fixation. This is of critical importance in the patients with head injuries and patients needing multiple surgical procedures. The ideal treatment for comminuted fractures of the mandible is by means of open reduction and internal fixation with Titanium miniplates.

Operating time and hospital stay are significantly reduced in the titanium miniplate group as compared to wiring group. There is higher incidence of infection and occlusion-related complications in the wiring group as compared to the titanium miniplate group.

Miniplating is more costly as compared to wiring, though the advantages are far more and there is a better patient compliance and acceptability with the titanium miniplate fixation. Although cost implications are important however it should be just one factor in making a decision regarding the best treatment for each patient even in developing countries.

\section{ACKNOWLEDGEMENTS}

Author would like to acknowledge the support provided by the Ex Head of our department Prof M A Darzi in conducting this study.

\section{Funding: No funding sources}

Conflict of interest: None declared

Ethical approval: The study was approved by the institutional ethics committee

\section{REFERENCES}

1. Malara P, Malara B, Drugacz J. Characteristics of maxillofacial injuries resulting from accidents: a 5 year review of the case records from department of Maxillofacial Surgery in Katowice, Poland. Head Face Med. 2006;2:27.

2. Patrocinio LG, Patrocinio JA, Borba BHC, Bonatti BD, Pinto LF, Vieira JV, et al. Mandibular fracture: analysis of 293 patients treated in the hospital of clinics, Federal University of Uberlandia. Rev Bras Otorrinolaringol. 2005;71(5):560-5.

3. Lee R, Robertson B, Manson P. Current epidemiology of facial injuries. Semin Plast Surg. 2002; 16:283.

4. Hagan EH, Huelke DF. An analysis of 319 case reports of mandibular fractures. J Oral Surg. 1961;19:93.

5. Huelke DF, Burdi AR. Location of mandibular fractures related to teeth and edentulous regions. J Oral Surg. 1964;22:396.

6. Huelke DF, Burdi AR, Eymon CE. Association between mandibular fractures and site of trauma, dentition and age. J Oral Surg. 1962;20:478.

7. Lachner J, Colanton JT, Waite PD. Open reduction and internal rigid fixation of subcondylar fractures via an intraoral approach. Oral Surg Oral Med Oral pathol. 1991;71:257-61.

8. Fox AJ, Kellman RM. Mandibular angle fractures: Two miniplate fixation and complications. Arch Facial Plast Surg. 2003;5:464-9. 
9. Bolourian R, Lazow S, Berger J. Transoral 2.0mm miniplate fixation of mandibular fractures plus 2 weeks' maxillomandibular fixation: A prospective study. J Oral Maxillofac Surg. 2002;60:167-70.

10. Ewers R, Harle F. Experimental and clinical results of new advances in the treatment of facial trauma. Plast Reconstr Surg. 1985;75(1):25-31.

11. Theriot BA, Van Sickels JE, Triplett RG, Nishioka GJ. Intraosseous wire fixation versus rigid osseous fixation of mandibular fractures: a preliminary report. J Oral maxillofac Surg. 1987;45:577-82.

12. Degala S, Gupta N. Tension band wiring a simplified approach for fracture reduction and intermittent stabilization. J Maxillofac Oral Surg. 2010;9(4):382-4.

13. Kellman RM. Repair of mandibular fractures via compression plating and more traditional techniques: a comparison of results. Laryngoscope. 1984;94:1560-7.

14. Zachariades N, Mezitis M, Rallis G. An audit of mandibular fractures treated by intermaxillary fixation, intraosseous wiring and compression plating. Br J Oral Maxillofac Surg. 1996;34:293-7.

15. Ozgenel GY, Bayraktar A, Ozbek S, Akin S, Kahveci R, Ozcan M. A retrospective analysis of 204 mandibular fractures. Turkish Journal of Trauma and Emergency Surgery. 2004;10(1):47-50.

16. Renton TF, Wiesenfeld D. Mandibular fracture osteosynthesis: a comparison of three techniques. $\mathrm{Br}$ J Oral Maxillofac Surg. 1996;34:166-73.

17. Hoffman WY, Barton RM, Price M, Mathes SJ. Rigid internal fixation v/s traditional techniques for the treatment of mandible fractures. $\mathrm{J}$ Trauma. 1990;30(1):1032-5.

18. Iizuka T, Lindqvist C, Hallikainen D, Mikkonen P, Paukku P. Severe bone resorption and osteoarthrosis after mini-plate fixation of high condylar fractures: a clinical and radiologic study of thirteen patients. Oral Surg Oral Med Oral Pathol. 1991;72:400-7.

19. Wang RC, Keech DR, Elkins TP, Russell P. The tension wire method: a simple, effective means of mandibular fixation. Arch Otolaryngol Head Neck Surg. 1998;124:448-52.
20. Ellis E, Muniz O, Anand K. Treatment considerations for comminuted mandibular fractures. J Oral Maxillofac Surg. 2003;61(8):86170 .

21. Abbas I, Ali K, Mirza YB. Spectrum of mandibular fractures at a tertiary care dental hospital in Lahore. J Ayub Med Coll. 2003;15(2):12-4.

22. Zargar M, Khaji A, Karbaksh M, Zarei MR. Epidemiology study of facial injuries during a 13 month of trauma registry in Tehran. Indian Journal of Medical Sciences. 2004;58(3):109-14.

23. Adeyemo WL, Iwegbu IO, Bello SA, Okoturo E, Olaitan AA, Ladeinde AL, et al. Management of mandibular fractures in a developing country: a review of 314 cases from two urban centers in Nigeria.World J Surg. 2008;32:2631-5.

24. Leach J, Truelson J. Traditional methods v/s rigid internal fixation of mandible fractures. Arch Otolaryngol Head Neck Surg. 1995;121:750-3.

25. Sindet-Pedersen S, Jensen J. Treatment of mandibular fractures with or without intermaxillary fixation: a comparative study. Oral Surg Oral Diagn. 1992;3:37-44.

26. Rubin JP, Yaremchuk MJ. Complications and toxicities of implantable biomaterials used in facial reconstructive and aesthetic surgery: a comprehensive review of the literature. Plast Reconstr Surg. 1997;100:1336-53.

27. Williams MD, Pearson MH, Milner SM. Complications in the use of compression plates in the treatment of mandibular fractures. Oral surg Oral Med Oral Pathol. 1991;72:159-61.

28. Abreu MER, Viegas VN, Ibrahim D, Valiati R, Heitz C, pagnoncelli RM, et al. Treatment of comminuted mandibular fractures: a critical review. Med Oral Patol Oral Cir Bucal. 2009;14(5):E24751.

29. Shetty V, Atchison K, Zigler C, Belin TR. Do the benefits of rigid internal fixation of mandible fractures justify the added costs? Results from a randomized control trial. J Oral Maxillofac Surg. 2008;66(11):2203-12.

Cite this article as: Baba PUF, Mohsin M, Bashir SA, Zaroo MI, Wani AH, Bilji AH. Should wiring be replaced by miniplating of mandibular fractures even in poor developing countries? Int Surg J 2016;3:1585-92. 